East African Medical Journal Vol. 80 No. 12 December 2003

PARTNER NOTIFICATION IN THE MANAGEMENT OF SEXUALLY TRANSMITTED INFECTIONS IN NAIROBI, KENYA

S. N. Wakasiakai, MSc, Researcher, Kenya AIDS Vaccine Initiative, P.O Box 19460, Nairobi, Kenya, J.J. Bwayo, MBChB PhD., Associate Professor, Department of Medical Microbiology College of Health Sciences, University of Nairobi, P.O Box 19676, Nairobi, Kenya, W. Khisa, MBChB, Consultant, Department of Obstetrics and Gynaecology, Kenyatta National Hospital, P.O Box 20723, Nairobi, Kenya, J. Mbithi, PhD, Department of Pure and Applied Sciences and C. Ogol, PhD, Department of Zoology, Kenyatta University, P.O Box 43844, Nairobi, Kenya

Request for reprints to: S.N. Wakasiaka, Kenya AIDS Vaccine Initiative, P.O. Box 19460, Nairobi, Kenya

\title{
PARTNER NOTIFICATION IN THE MANAGEMENT OF SEXUALLY TRANSMITTED INFECTIONS IN NAIROBI, KENYA
}

\author{
S. N. WAKASIAKA, J. J. BWAYO, K. WESTON, J. MBITHI \\ and C. OGOL
}

\begin{abstract}
Objective: To assess utilization of partner notification as a tool in prevention and control of Sexually transmitted infections in Nairobi City Council clinics.

Design: A cross-sectional study carried out between April and September 2000.

Setting: Nairobi City Council health clinics were stratified into eight administrative divisions and a total of $\mathbf{1 6}$ out of $\mathbf{5 4}$ primary health clinics with at least four STIs patients per day were selected. A standard questionnaire was administered to every fourth patient with clinical diagnosis of STIs who gave consent on exist. Sexual partners referred by index cases during the five day period from each clinic were also enrolled into the study. An additional questionnaire was administered to HCP who were managing STIs patients and their sex partners.

Results: Of 407 STIs patients recruited between April and September 2000, 20.6\% were primary and $2 \%$ were secondary referrals giving an average referral rate of $23 \%$. Respondents with multiple sex partners were less likely to refer their partners compared to those who had one partner $(17.9 \%$ vs $82.1 \%$, p < 0.005$)$. Counseling of STI patients on the importance of partner referral was more effective than issuing referral cards alone $\mathbf{7 2 . 8 \%}$ vs $56.8 \% \% \mathrm{p}=<\mathbf{0 . 0 0 6})$. Barriers to partner notification included partners being out of town $(44.6 \%)$ fear of quarrels and violence from partners $(32.5 \%)$ and casual partners $(15.1 \%)$ whose sex partners were unknown.

Conclusion: Counseling and understanding of STIs patients on the need to treat all sexual partners is pivotal to the success of partner referral.
\end{abstract}

\section{INTRODUCTION}

Partner notification and condom use, preventive indicator seven(1) are components of sexually transmitted infections (STIs) control programme. As a public health strategy, the sex partners of the index case are notified, counseled and offered services(2). This process breaks the chain of spread of STIs from symptomatic and asymptomatic patients thus ensuring re-infection does not occur. In this way, the burden of a disease in the community is reduced(3).

Utilization of partner notification in case management is limited. This is because health care providers ( $\mathrm{HCPs}$ ) often dismiss notification due to the amount of time involved in counseling and educating the patients(4). The long incubation period for some sexually transmitted infections form major confounding factors in partner notification. Sexually transmitted infections with short incubation period such as gonorrhea and chlamydia, present good notification rates(3).

A cross-sectional study was conducted within Nairobi City Council health clinics to assess utilization of partner notification as a tool for prevention and control of STIs by comparing the number of index cases and sexual contacts treated for STIs.

\section{MATERIALS AND METHODS}

Approval was obtained from the Kenyatta National Hospital Ethics and Scientific Committees to conduct the study among Nairobi City Council health clinics. Health facilities were stratified according to administrative divisions and 16 out of 54 primary health clinics with at least four STIs patients per day were selected. An exit interview was conducted on every fourth clinically diagnosed STI patient presenting to the clinic within five working days who gave a verbal consent. Using a standard questionnaire, data were collected on: social and demographic characteristics, presenting STIs complaints, duration of symptoms, and sexual behavior. Information was collected on whether they were counseled by HCPs regarding the nature of illness, issued with notification slips to notify and refer their partners to the clinic for treatment. Only patients who were referred, assessed and treated within the five day period spent at each clinic are included in the analysis. In this study an index patient refers to the first STIs patient who presented himself/herself for treatment, a primary patient is the first referral, secondary patient is the second referral and the tertiary patient is the third referral.

Although there were many HCPs from the 16 study clinics who were eligible, only those who attended to STI patients within the five day study period were enrolled into the study. A separate questionnaire was used to collect data on the knowledge and notification practices between HCPs. 


\section{RESULTS}

Social Demographic Characteristics: A total of 407 STIs patients were enrolled into the study between April and September 2000 with a mean age of $27.6 \pm 7.5$ (range 17 to 54 ) years. Of these $58.7 \%$ were women, $62.9 \%$ married and $33.7 \%$ were single (Table 1 ).

Most of the patients had formal education as follows: $31.4 \%$ secondary, $27.2 \%$ primary and $1.5 \%$ college/university education. There were more Protestants than Catholics (56\% vs. $32 \%)$. A third of STIs patients were below poverty line; $12.6 \%$ earned less than US\$27.00 a month and $17.5 \%$ had no regular income with the majority $(19.4 \%)$ being housewives. Casual workers were among $50.7 \%$ who earned between US\$27108 while small business people were among $19.2 \%$ that earned over US\$108.00 per month.

Patients took a long time before seeking STIs treatment. Only $25.8 \%$ sought treatment in less than a week compared to $31.4 \%$ who took more than four weeks. Presenting symptoms varied between sexes with predominant symptoms in females being vaginal discharge (38.8\%), lower abdominal pain $(23.8 \%)$ and genital ulcers (17.6\%) while urethral discharge (26\%) and genital ulcers $(29.2 \%)$ were the complaints in males (Table 2).

Practices of Health Care Providers: Of the 36 HCPs (33 nurses, two doctors and one clinical officer) enrolled into the study, $77.8 \%$ were females aged between 25 and 54 years with working experience ranging between 1 and 31 years. All of the HCPs had in-service training in syndromic management of STIs in the past 1 to 12 years. Eagerness to upgrade their skills was shown by 97.2\% of HCPs who requested for training in STDs/HIV/ AIDS management $(41.7 \%)$ and in counseling (36.1\%). Training in counseling would seem a priority given the nature of their work and the fact that only $8.3 \%$ had prior training in counseling.

Health care providers had a copy of the flow chart and $91.7 \%$ followed the Ministry of Health National Guidelines on STIs syndromic management. From interviews HCPs, $90.3 \%$ advised patients on partner notification and $82.1 \%$ provided contact / referral cards. Further $86.1 \%$ provided education on compliance $(51.6 \%)$, and use of drugs (54.\%) to STIs patients and warned them on the risk of HIV/AIDS $(83.3 \%)$. In addition $61.0 \%$ stated that they provided advice and instructions (44.4\%) on the use of and provided condoms (91.7\%) to STIs patients.

Table 1

Demographic Characteristics of Patients

\begin{tabular}{|c|c|c|}
\hline Variable & Frequency & Percentage \\
\hline \multicolumn{3}{|l|}{ Age in years } \\
\hline $15-20$ & 59 & 14.4 \\
\hline $21-25$ & 127 & 31.3 \\
\hline $26-30$ & 126 & 31 \\
\hline $31-35$ & 48 & 11.9 \\
\hline $36-40$ & 23 & 5.7 \\
\hline $41-45$ & 13 & 3.2 \\
\hline $46-50$ & 10 & 2.5 \\
\hline \multicolumn{3}{|l|}{ Gender } \\
\hline Male & 168 & 41.3 \\
\hline Female & 239 & 58.7 \\
\hline \multicolumn{3}{|l|}{ Marital status } \\
\hline Married & 256 & 62.9 \\
\hline Single & 151 & 37.1 \\
\hline \multicolumn{3}{|l|}{ Religion } \\
\hline Protestant & 228 & 56 \\
\hline Catholic & 130 & 31.9 \\
\hline Others & 49 & 12.1 \\
\hline \multicolumn{3}{|l|}{ Income per month } \\
\hline None & 71 & 17.5 \\
\hline$<200$ & 51 & 12.6 \\
\hline $2001-8000$ & 206 & 50.7 \\
\hline$>8000$ & 78 & 19.2 \\
\hline \multicolumn{3}{|l|}{ Occupation } \\
\hline Unemployed & 132 & 32.4 \\
\hline Unskilled & 64 & 15.7 \\
\hline Skilled & 75 & 18.4 \\
\hline Business & 136 & 33.5 \\
\hline \multicolumn{3}{|l|}{ Education level } \\
\hline None & 20 & 4.9 \\
\hline Primary & 155 & 38.1 \\
\hline Secondary & 211 & 51.8 \\
\hline College & 21 & 5.2 \\
\hline
\end{tabular}


Table 2

Presenting complaint by gender

\begin{tabular}{|c|c|c|c|}
\hline Presenting STDs Complaint/Symptom & Male $(\%)$ & Female $(\%)$ & P-Value \\
\hline Urethral Discharge & $106(26)$ & - & \\
\hline Vaginal Discharge & 0 & $158(38.8)$ & \\
\hline Genital Ulcer Disease & $49(29.2)$ & $42(10.3)$ & $\mathrm{P}>0.06$ \\
\hline Genital Pruritis & $24(18.3)$ & $55(13.5)$ & $\mathrm{P}>0.28$ \\
\hline Lower abdominal pain & $14(8.3)$ & $152(37.3)$ & $\mathrm{P}>0.05$ \\
\hline
\end{tabular}

*Some patients presented with multiple symptoms

Table 3

Health Care Providers and referral practices

\begin{tabular}{|c|c|c|c|c|}
\hline \multirow{2}{*}{$\begin{array}{l}\text { Attribute of } \\
\text { the Respondent }\end{array}$} & \multicolumn{4}{|c|}{ Profession of HCPs } \\
\hline & Doctors $(\%)$ & Nurses $(\%)$ & Clinical officers $(\%)$ & P-value \\
\hline \multicolumn{5}{|l|}{$\begin{array}{l}\text { Gender of } \\
\text { Patients treated }\end{array}$} \\
\hline Male & $87(51.2)$ & $20(11.8)$ & $37.1(63)$ & $\mathrm{P}<0.00$ \\
\hline Female & $4(1.7)$ & $229(96.6)$ & $1.7(4)$ & \\
\hline \multicolumn{5}{|c|}{ Patients knowledge on diagnosis } \\
\hline Yes & $7(7.7)$ & $212(85.1)$ & $6(9)$ & $\mathrm{p}<0.00$ \\
\hline No & $84(92.3)$ & $37(14.9)$ & $91(61)$ & \\
\hline \multicolumn{5}{|c|}{ Explaining mode of spread } \\
\hline Yes & $17(18.7)$ & $237(95.2)$ & $14(20.9)$ & $\mathrm{P}<0.00$ \\
\hline No & $74(81.3)$ & $12(4.8)$ & $53(79.1)$ & \\
\hline \multicolumn{5}{|c|}{ Drugs issued for partners } \\
\hline Yes & $1(1.1)$ & $30(12)$ & $0(0)$ & \\
\hline No & $90(98.9)$ & $219(88)$ & $67(16.5)$ & $\mathrm{p}<0.01$ \\
\hline \multicolumn{5}{|c|}{ Partner notification cards issued } \\
\hline Yes & $3(3.3)$ & 121 (48.6) & $3(4.5)$ & $\mathrm{P}<0.00$ \\
\hline No & 88 (96.7) & $128(51.4)$ & $64(95.5)$ & \\
\hline
\end{tabular}

Table 4

Partner notification practices

\begin{tabular}{|c|c|c|c|}
\hline \multirow{2}{*}{$\begin{array}{l}\text { Respondent } \\
\text { Characteristic }\end{array}$} & \multicolumn{2}{|c|}{ Partner Notification Practices } & \multirow[t]{2}{*}{ P-value } \\
\hline & Referred $(\%)$ & Did not Refer $(\%)$ & \\
\hline \multicolumn{4}{|l|}{$\begin{array}{l}\text { Willingness to bring } \\
\text { partners for treatment }\end{array}$} \\
\hline Yes & $67(72.8)$ & $179(56.8)$ & $\mathrm{P}<0.30$ \\
\hline No & $25(27.2)$ & $136(43.2)$ & \\
\hline \multicolumn{4}{|l|}{$\begin{array}{l}\text { Issued drugs } \\
\text { for partners }\end{array}$} \\
\hline Yes & $0(0)$ & $92(100)$ & $\mathrm{P}<0.02$ \\
\hline No & $31(9.8)$ & 284(90.2) & \\
\hline \multicolumn{4}{|c|}{ Issued partner notification cards } \\
\hline Yes & $35(38)$ & $92(29.2)$ & $\mathrm{P}<0.108$ \\
\hline No & $57(62)$ & 223(70.8) & \\
\hline \multicolumn{4}{|c|}{ Respondents with multiple sex partners } \\
\hline Yes & $15(17.9)$ & $106(38.5)$ & $\mathrm{P}<0.045$ \\
\hline No & $69(82.1)$ & $169(61.5)$ & \\
\hline \multicolumn{4}{|l|}{ Referral by marital status } \\
\hline Single & 16(11.7) & $121(88.3)$ & \\
\hline Married & $73(28.5)$ & $183(71.5)$ & $\mathrm{P}<0.30$ \\
\hline Separated/divorced & $3(23.1)$ & $10(76.9)$ & \\
\hline \multicolumn{4}{|l|}{ Referral by Counseling } \\
\hline Counseled & $67(72.8)$ & $179(56.8)$ & $\mathrm{P}<0.06$ \\
\hline Not counseled & $25(27.2)$ & $136(43.2)$ & \\
\hline
\end{tabular}


Table 5

Referral by duration of symptoms and occupation

\begin{tabular}{|c|c|c|c|c|}
\hline & $\begin{array}{l}\text { Referred } \\
\text { Frequency }\end{array}$ & $\%$ & $\begin{array}{l}\text { Not Referre } \\
\text { Frequency }\end{array}$ & $\%$ \\
\hline \multicolumn{5}{|l|}{ Duration of symptoms } \\
\hline Less than one week & 14 & 13.3 & 91 & 86.7 \\
\hline $1-2$ weeks & 23 & 21.3 & 85 & 78.7 \\
\hline $3-4$ weeks & 11 & 16.7 & 55 & 83.3 \\
\hline \multicolumn{5}{|l|}{ Referral by occupation } \\
\hline Unemployed & 10 & 10.9 & 29 & 9.2 \\
\hline Housewife & 28 & 30.4 & 51 & 16.2 \\
\hline Casual & 10 & 10.9 & 44 & 14 \\
\hline Skilled artesian & 8 & 8.7 & 28 & 8.9 \\
\hline CSWs & 1 & 1.1 & 16 & 5.1 \\
\hline Business & 28 & 30.4 & 91 & 28.9 \\
\hline Student & 0 & 0 & 14 & 4.4 \\
\hline Office & 7 & 7.6 & 32 & 10.2 \\
\hline Others & 0 & 0 & 10 & 3.2 \\
\hline Total & 92 & 22.6 & 315 & 77.4 \\
\hline
\end{tabular}

Table 6

Barriers to partner referral

\begin{tabular}{lll}
\hline Barrier & Number of Cases & $\%$ \\
\hline Fear of quarrels & 46 & 27.7 \\
Fear of violence & 8 & 4.8 \\
Partner out of town & 74 & 44.6 \\
Casual relationship & 25 & 15.1 \\
Partner treated elsewhere & 3 & 1.8 \\
\hline
\end{tabular}

Regarding STIs patients, more $(58.5 \%)$ male patients consulted doctors and clinic officers who were mostly males while female patients sought treatment from nurses $(92.3 \%)$ most of whom were females. Of patients interviewed on exit, $68.8 \%$ admitted that HCPs had given them health education advice on STIs/HIV, need to refer sexual partners for treatment $(83.5 \%)$ and warned them against the risk of HIV/AIDS (61.2\%). Out of these $55 \%$ were informed about the diagnosis of their STIs mode of spread and $65.8 \%$ were told about their treatment.

Only a small number of STIs patients had been given condoms $(17.7 \%)$ and instructions on how to use them $(16.5 \%)$. Similarly drugs for the sex partners and notification cards were given only to $7.6 \%$ and $31.2 \%$ of STIs patients respectively (Table 3).

Partner Referral Practice: The index cases (84\%) formed the bulk of respondents interviewed with $20.6 \%$ primary and $2 \%$ secondary referral patients. Partner notification was positively correlated with whether one was counseled on the need to referrer partners or not (72.8\% vs $56.8 \%, \mathrm{p}<0.006)$ and negatively correlated with having multiple sexual partners $(17.9 \%$ vs $38.5 \%$ $\mathrm{p}<0.005)$ and being issued with drugs for the partners $(0.0 \%$ vs $9.8 \%)$. There was no significant correlation with STIs patient's willingness to bring partner for treatment, being issued with notification cards, presentation and duration symptoms, occupation and marital status. Housewives were more likely to be referred (30.4\% vs $16.2 \%)$ probably because their sex partners are known and concerned about getting reinfected.

Table 6 summarises the reasons given by STIs patients for not referring their sexual partners for treatment. Barriers to partner notification included partners being out of town $44.6 \%$, fear of quarrels and violence from partners $32.5 \%$ and causal partners $15.1 \%$ whose contacts were unknown to the STIs patients.

\section{DISCUSSION}

In this study three factors that influence partner notification are compared; practice of STIs patients, practice of health care providers, barriers to notification, and partner referral rate. Over a third of the respondents took more than four weeks before seeking treatment. High generation rate from individuals with high rate of sex partner change and long duration of illness before treatment are responsible for maintaining STIs rates in a community( 3 ).

More than half of the men in this study reported having multiple sex partners during the symptomatic 
period. The practice was most common among married men $(51.1 \%)$ in 71 cases. This implies that married men who did not refer all partners continue infecting and being re-infected by sexual partners thus maintaining STIs in the community and creating resistance to therapeutic substances $(7,8)$. Untreated partners continue to serve as a reservoir for pathogenic organisms, such scenario complicates prevention and control of STI $(5,9)$. Since the Kenyan law is silent on STIs treatment in the general population individuals take personal decisions as to when, where and how to seek treatment.

The nature of infection influences the time to seek treatment(10). Patients with short incubation period such as gonorrhoea and chlamydia presented themselves in less than a week compared to those with genital ulcer diseases (syphilis and chancroid) who presented after four weeks. A patient presenting with discharge experiences discomfort in the early stage of the disease either during micturation or during sexual intercourse, prompting him/her to seek medical care almost immediately. Majority of patients who were referred by index cases were asymptomatic with non-specific signs and symptoms such as backache $(40.5 \%)$, headache and fever $(38.3 \%)$.

Alternative strategies of educating patients on control and prevention of STls are needed, especially on partner notification. When respondents were asked to give suggestions on methods that can be utilized to improve notification, $37.8 \%$ did not offer any suggestions, and $1.2 \%$ pointed out that men should be targeted because of having multiple sex partners and frequenting commercial sex workers. Encouraging voluntary counseling and testing for STIs/HIV/AIDS which, can reduce STIs caseload in communities has been proven feasible in the prevention and control of STls(11).

Training of health care providers can increase knowledge and skills significantly, and improve control and prevention of STDs/HIV/AIDS. The effectiveness of training HCPs in syndromic management is confirmed in the study, by the knowledge and practices exhibited by HCPs. Pre-service and continuous medical education is essential for the health care providers to perform their duties effectively. However, training must be accompanied by appropriate supplies and effective supervision.

Although the counseling component in syndromic STIs management does not stipulate precise topics to be covered in STIs education, the counseling strategy has been shown to improve referral. In this study a significant number $(72.8 \%)$ of STIs patients referred their sex partners following counseling session by the HCPs compared to those who did not refer. Referral can be enhanced further when HCPs address specific key topics during the counseling sessions $(9,12)$. Although partner notification is an essential tool in prevention and control of sexually transmitted infections, it is difficult for people to notify their sexual partners unless they are well informed about diagnosis, mode of transmission and the need to treat all partners.

Partner notification can be an effective tool in STIs management if barriers are identified and removed. As have been shown in the other studies(13), majority of respondents were willing to refer their partners for treatment. Due to time limitation it was not possible to ascertain whether or not partners were eventually treated at the same clinic or elsewhere. Various reasons were given by those who could not refer their partners included: $44.6 \%$ partners were out of town, $32.7 \%$ fear of quarrels and violence, and $15.1 \%$ casual partners. Of particular public health interest and concern are claims that partners were either out of town or of unknown address who could not be contacted and therefore continued to spread infections. These findings indicate that individuals are not ready to accept the responsibilities concerning the STIs problem; instead patients give reasons that justify their actions. Such behaviour help individuals cope with the problem without necessarily solving the root cause, this may explain the explosive prevalence of STIs/HIV/AIDS in Kenya(14). In such circumstance health care providers should be mandated to notify contact partners directly without consent of the infected persons. There is need for long- term follow up studies of STIs/HIV/AIDS patients in order to establish other factors that hinder notification such as cultural beliefs and values.

Partner notification used alone may not be an effective tool in prevention and control of STls. These results compare well with other studies, which shows that partner notification alone cannot be an effective tool in control of STIs(15-17). Alternative strategies are therefore needed to compliment partner referral.

\section{REFERENCES}

1. World Health Organization Consultation Document. Global programme on AIDS; Estimated Surveillance report. 1989; 22:117-212.

2. Frances, M., Rebecca, F. and Anne, M. The role and effectiveness of partner notification in STD control. Sexually Trans. Dis. published report, University of London Medical School. 1996; 28:247-252.

3. Katz, B. P., Caine, V. A., and Jones, R. B. Evaluation of field follow up in a sexually transmitted clinic for patients with Neisseria Gonorrhoea and Chlamydia Trachomatis. Sexually Trans. Dis. 1992; 19:99-103.

4. Moses, S., Muia, K., Bloodly, J. E. Sexual behavior in Kenya: Implications of sexually transmitted disease transmissions and control. Social Sci. Med. J. 1994; 39:1649-1656.

5. Faxelid, E., Tembo, G., and Ndulo, J. Individual counseling with Sexually Transmitted Diseases. A way to improve partner notification on Zambian setting. Sexually Trans. Dis. 1996; 23: 289-292.

6. Gichangi, P., Achola, J., Bwayo, J. J. and Kigondu, C. Partner notification of pregnant women infected with syphilis in Nairobi, Kenya. International J. STD and AIDS. 2000;1:257-261.

7. Chowdhury, S. N., Gomes, J. V., and Hossanin, S. M. Strengthening STD services for men in an urban clinic based program. Population Council. 1997 Jun. Xii.40. 
8. Wyckoff, R. F., Heath, C. W., and Hollis, S. L. Contact tracing to identify human immunodeficiency virus in a rural community. JAMA. 1988; 259:3563-3566.

9. Osoba, A. O., Ogubanjo, B. O., and Auzu, M. C. Reinforcement of health education and counseling by doctors in treatment and control of sexually transmitted diseases. Genitourin. Med. 1986; 62:53-55.

10. Steen, R. Studies show partner notification contributes to STD control. AIDS captions. 1996; 3:28-30.

11. Toomey, K. E., and Bayer, R. HIV prevention and the two faces of partner notification. Amer. J. public Health. 1992; 82: $1158-1164$.

12. Caldwell, J. C., Anarfi, J. K., and Caldwell, P. Mobility, migration, sex, STD and AIDS. In An essay on sub-Saharan Africa with other parallels. Oxford University Press. $14^{\text {th }}$ Edition, England. 1997; 41-54.
13. AIDs in Kenya, Background projections impact, interventions policy. Nascop. $5^{\text {th }}$ Edition, 1999; 15-35.

14. United Nations program on HIV/AIDS (UNAIDS), Summary of best practices in Africa, Issue No.2, Geneva, Switzerland, 2000; 28-31.

15. Mukaire, J., Kalikwani, F., and Maggwa, B. N. Integration of STI and HIV/AIDS services with MCH-FP services. A case study of the Busoga Diocese, Family Life Education program, Uganda. Population Council. 1997; 5:29-32.

16. Gieseke, J., Ramstedt, K., and Granath, F. Efficacy of partner notification for HIV infection. Lancet. 1991; 338:1096-1099.

17. Faxelid, E. A., and Ramstedet, K. M. Partner notification in context; Sweedish and Zambia experiences. Social Sci. and Medicine.1994; 44:1239-1243. 